\title{
NeW Design of Polyurethane FoAm Moulds For VibRATIONAL CASTED REFRACTORY MATERIALS
}

\author{
Aleš Herman, František Václav Štourač, Jiří Kyncl \& Libor Beránek
}
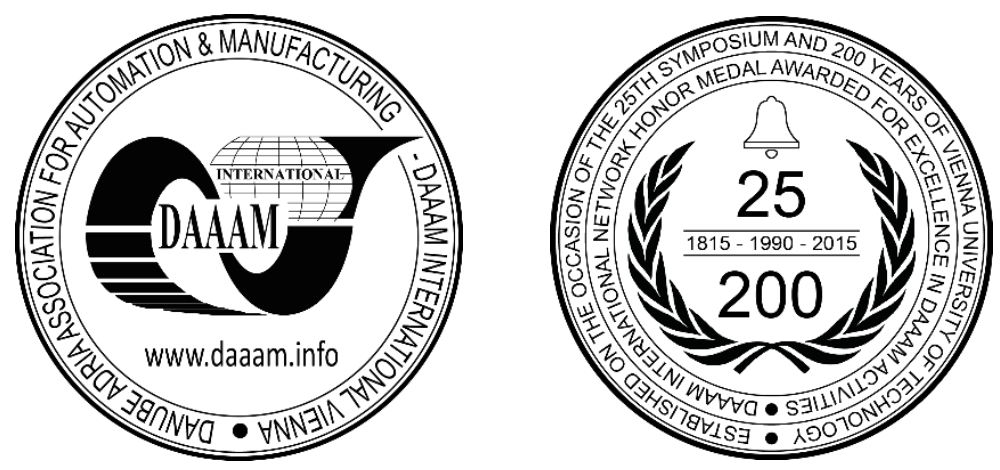

This Publication has to be referred as: Herman, A[les]; Vaclav Stourac, F[rantisek]; Kyncl, J[iri] \& Beranek, L[ibor] (2018). New Design of Polyurethane Foam Moulds for Vibrational Casted Refractory Materials, Proceedings of the 29th DAAAM International Symposium, pp.1231-1238, B. Katalinic (Ed.), Published by DAAAM International, ISBN 978-3-902734-20-4, ISSN 1726-9679, Vienna, Austria

DOI: $10.2507 / 29$ th.daaam.proceedings. 178

\begin{abstract}
This paper describes problems of testing and development of new mould types for refractory vibrational casting parts for melting aggregates (glass furnaces, limekilns, etc.). The main problem of the existing moulds design is in their cost and relatively complex production. We need to significantly reduce costs of production and shorten the time of delivery to the customer (now the reaction time is about $1-2$ months, the demand from customers is about $1-2$ weeks)
\end{abstract}

Keywords: refractory material; casting mould; polyurethane foam; material testing

\section{Introduction}

This paper deals with vibrational casting refractory parts production for e.g. glass furnaces (see Fig. 1). The casting of refractory materials to shaped bricks is very similar to casting of concrete prefabricate. In mixer there is prepared the mixture from refractory material by prescription with a certain proportion of binders. From the mixer the mixture is transported to pouring field. There is positioned vibrational table with prepared mould. Into this mould the prepared refractory mixture is poured. For better compaction and better surface quality of refractory mixture, the table vibrates (the vibration enable to climb gas bubble to high open surface of mould). Vibration is making total compacting of mixture in mould. The first step is the drying of the mixture in mould and take several hours (there is a chemical reaction to harden the mixture). The second step is represented by disassembly of mould and the refractory bricks are drown out. Then bricks burning follow.

During hardening starts in mould exothermic reaction (drying process). During this process, the refractory mixture is shrinking accordingly. [1] In case, that mould is assembly form difficulty shapes parts, during drying process are arisen of cracks on bricks surface. From this reason is need to make these mould parts from flexible material, which is eliminated the pressure arisen during drying and hardening process. [2] The flexible parts are made of polyurethane (hereinafter referred to as PUR) rubber with thickness of wall between 5 to $10 \mathrm{~mm}$. The production of PUR rubber parts is the main reason why is to extend the time of production and therefore make the higher mould cost also. [3,4] 
The production of moulds for refractory bricks is very similar to production of foundry core boxes. The mould base is dismountable case with shaped inserts are put into.

The main disadvantage of mould production:

- Long production time

- Need for a skilled worker - patternmaker

Both of these disadvantages represent high cost for mould production and worsening the producer competitiveness from aspect a new type shape refractory bricks production reaction speed. [5,6] The aim of the experiment is to find a solution how to speed up and reduce the production of refractory bricks.

\section{The suggest a new type of material for moulds}

During study technology of production concrete prefabricates we found beyond the procedure described above the possibility of using next materials, where the following criteria had to consider:

- Seriousness - the design directly subdivides the number of pieces

- Appropriate shape of the refractory bricks - different thickness of walls, cavity, protruding and deflected outer shapes

- $\quad$ Testing appropriate combinations of materials and coating systems in mould.

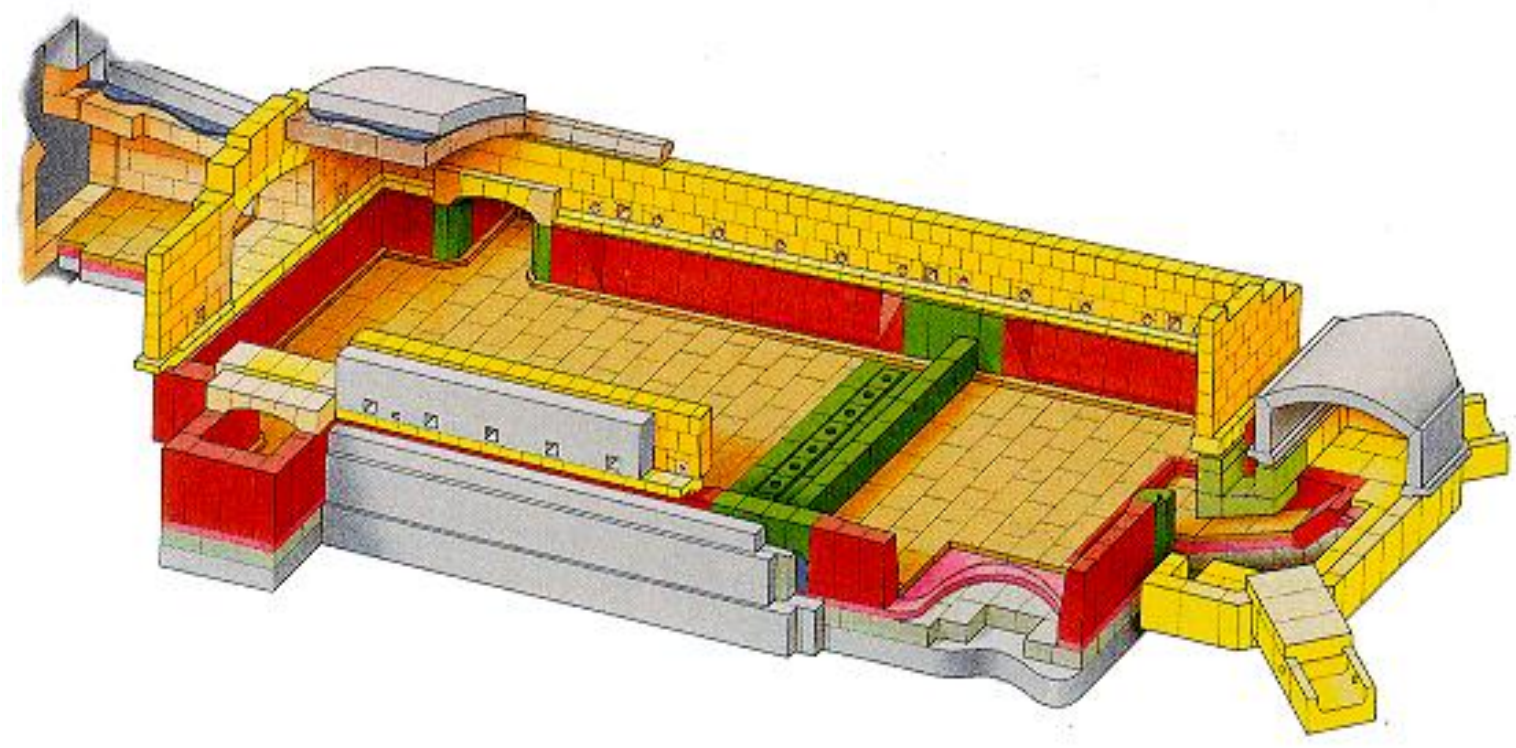

Fig. 1. Section by gas glass melting furnace - a scheme of folding refractory bricks [7]

For piece production, we designed to use 3D printing technology. As an alternative are production of dimensionally unified wooden frames, inserts are place into which disposable polystyrene (PS). This inserts are possible to cut (or to destroy) after during phases of drawing out refractory bricks. [8,9] For serial production was suggested the using of inserts from foam material. In this paper deals with only this type of moulds for serial production.

The main advantages of foam material

$>$ Select the material according to the planned series - can be controlled the foam density

$>$ It is possible to use a scale model from PS that can be cut or destroy

$>$ The mold can be foamed at once and cut or destroy after foam

$>$ Mould can be reinforced PS, plywood, etc.

The main disadvantages of foam material

$>$ A need to test the density correlation and degradation of the foam (due to repetition of production)

$>$ A reaction with refractory mass

The suggest of tested material

$>$ Epoxy foam (resin LG100, hardener HG 30 - - mixing ratio 100:40, and foaming agent FC3 mixing ratio 1 $5 \%$ (costs for volume $1 \mathrm{~m}^{3}-161$ hundreds CZK)

$>$ Foam PUR - density $50-150 \mathrm{~kg} / \mathrm{m}^{3}$ - foaming ratio up 20x (costs for volume $1 \mathrm{~m}^{3}-5-15$ hundreds CZK). 


\section{Experiment - description}

For experiment there was suggested mould of unit volume $11\left(1 \mathrm{dm}^{3}\right)$ - mainly because of reason of next easy recalculating of mould sizes - see Fig. 2.
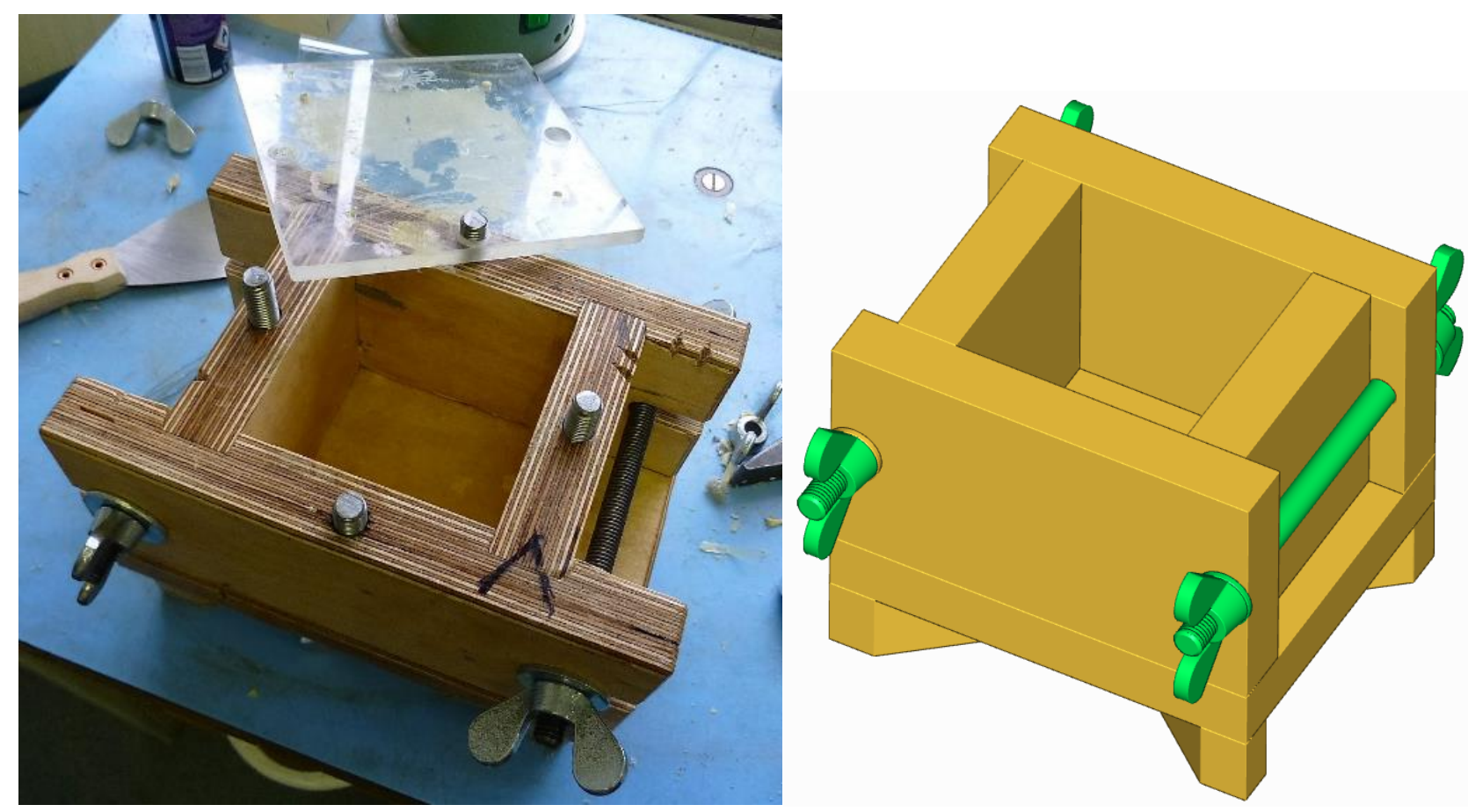

Fig. 2. Real shape of testing mould (on left), CAD model (on right)

Experimental materials:

1. PUR1 - material PUR Izopianol 50/110 (assembled from ingredients A, B - mixed ratio 1:1) - density 100 $120 \mathrm{~kg} / \mathrm{m}^{3}$, foaming ratio $10 \mathrm{x}$ ).

2. PUR2 - material PUR Izopianol 50/48 (assembled from ingredients A, B - mixed ratio 1:1) - density 48 - 53 $\mathrm{kg} / \mathrm{m}^{3}$, foaming ratio $20 \mathrm{x}$ ).

For both materials (in experiment the several important time periods were measured):

$>$ Starting time foaming reaction : $42 \mathrm{~s}$

$>$ Gel time of foam (end reaction) : $200 \mathrm{~s}$

$>$ Tackfree time : $420 \mathrm{~s}$

There was a large number of experiments, where:

$>$ various mixing ratios were tested,

$>$ the effect of various separation agents was tested

$>$ using of PS inserts in mould

$>$ using of plastic shapes with protrusion (for checking of filling difficulty shapes mould)

$>$ machining of shape and testing different type of catching for obtaining of smooth surface (under Ra $0,4 \mu \mathrm{m}$ )

As separator was tested:

$>$ Painting covering foil from HDPE - thickness $6 \mu \mathrm{m}$

$>$ Painting covering foil from HDPE - thickness $12 \mu \mathrm{m}$

$>$ Painting covering foil from HDPE - thickness $30 \mu \mathrm{m}$

$>$ Painting covering foil from HDPE - thickness $50 \mu \mathrm{m}$

$>$ Bee wax floor hard paste

For experiment there were prepared precision measured quantity of components A and B (into branded containers), was prepare moulds wit separator (see Table 1). Due to the large scale of experiments, in this paper describe representative examples of produced samples only. 


\begin{tabular}{|l|l|l|l|l|}
\hline Sample Nr. & Total volume (l) & Volume ingr. A (l) & Volume ingr. B (l) & Separator \\
\hline 6 & 0,16 & 0,08 & 0,08 & Foil $6 \mu \mathrm{m}$ \\
\hline 7 & 0,18 & 0,09 & 0,09 & Foil $6 \mu \mathrm{m}$ \\
\hline 8 & 0,2 & 0,1 & 0,1 & Foil $6 \mu \mathrm{m}$ \\
\hline 12 & 0,16 & 0,08 & 0,08 & Foil $12 \mu \mathrm{m}$ \\
\hline 13 & 0,18 & 0,09 & 0,09 & Foil $12 \mu \mathrm{m}$ \\
\hline 14 & 0,2 & 0,1 & 0,1 & Foil $12 \mu \mathrm{m}$ \\
\hline 22 & 0,14 & 0,07 & 0,07 & Foil 30 $\mu \mathrm{m}$ \\
\hline 23 & 0,15 & 0,075 & 0,075 & Foil 30 $\mu \mathrm{m}$ \\
\hline 24 & 0,16 & 0,08 & 0,08 & Foil 30 $\mu \mathrm{m}$ \\
\hline 31 & 0,18 & 0,09 & 0,09 & Foil $50 \mu \mathrm{m}$ \\
\hline 32 & 0,2 & 0,1 & 0,1 & Foil $50 \mu \mathrm{m}$ \\
\hline 33 & 0,1 & 0,05 & 0,05 & Foil $50 \mu \mathrm{m}$ \\
\hline 51 & 0,18 & 0,09 & 0,09 & Wax \\
\hline 52 & 0,2 & 0,1 & 0,1 & Wax \\
\hline 53 & 0,16 & 0,08 & 0,08 & Wax \\
\hline
\end{tabular}

Table 1. The example chosen good experiments for material PUR 1

The same method were used for evaluation of foaming material PUR 2 (the influence of volume pats A and B is demonstrate on Fig. 3, where is possible see samples 1 to ten from material PUR1 - with different using volume (the sample 1, 2, 3 and 6 not filling mould - the volume was too small). In the first experiments with PUR materials there were produced and documented 60 samples (from materials PUR1a PUR 2).

No significant differences were observed between PUR1 and PUR2 when casting samples. At certain volumes and concentrations, PUR2 had a better surface. On the other hand, specimens of PUR1 material were toughened (finger-tospecimen) harder than samples from PUR2. PUR2 was also a simpler cast-slower reaction. This initial stage of testing PUR materials did not exclude either of the selected and tested materials.

The quality of the sample is significantly influenced by the volume of the mixed mixture and by the ratio of the individual components in the preparation of the mixture. These initial tests set a narrower range of the appropriate volume of the blended mixture (degree of foaming) and the ratio of its components (at this stage of the experiment very close to the 1: 1 ratio) for further testing.

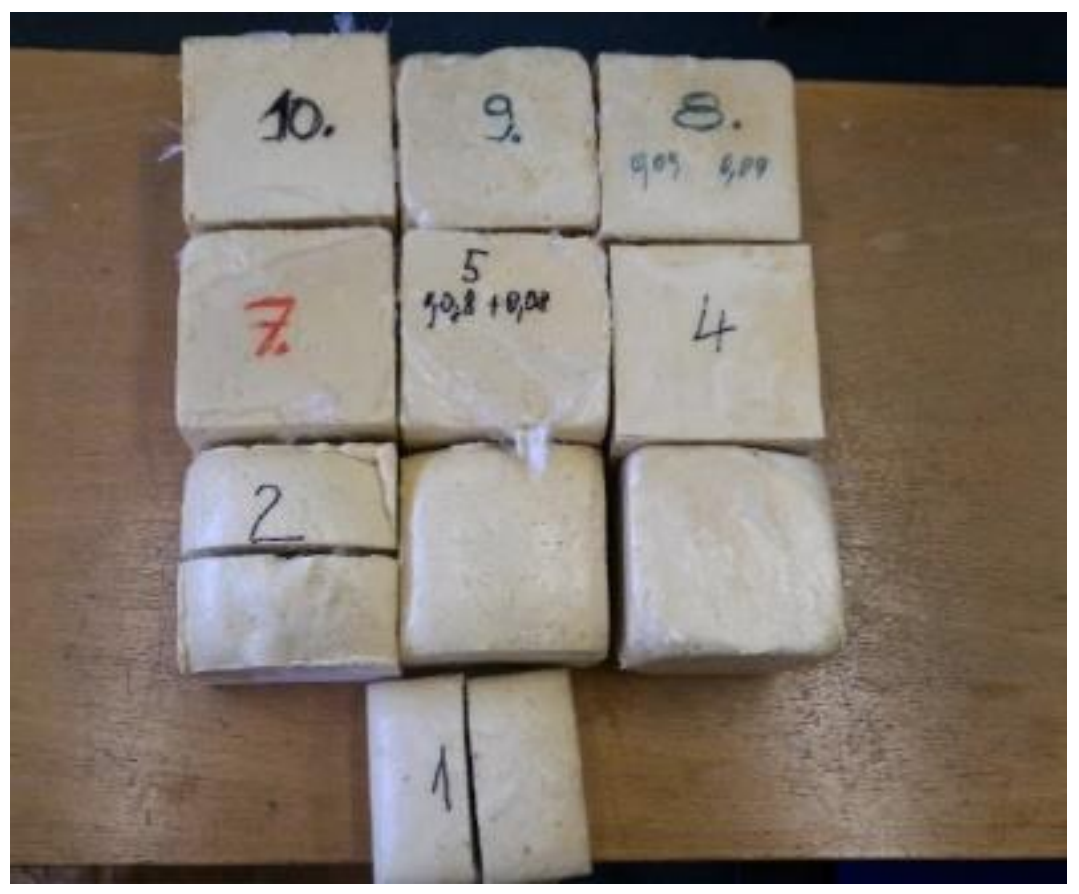

Fig. 3. Samples of bricks from material PUR 1 


\begin{tabular}{|l|c|c|}
\hline & PUR 1 & PUR 2 \\
\hline Surface quality & 3 & 4 \\
\hline Foaming of space & 3 & 3 \\
\hline Cost (small package) & $14000 \mathrm{CZK} / \mathrm{m}^{3}$ & $5400 \mathrm{CZK} / \mathrm{m}^{3}$ \\
\hline Foil 6 $\boldsymbol{\mu m}$ & 2 & 3 \\
\hline Foil 12 $\boldsymbol{\mu m}$ & 3 & 4 \\
\hline Foil 30 $\boldsymbol{\mu m}$ & 3 & 4 \\
\hline Foil 50 $\boldsymbol{\mu m}$ & 2 & 3 \\
\hline Wax & 4 & 5 \\
\hline
\end{tabular}

Table 2. The evaluation of first phases of experiment ( 1 - the worst, 5 - the best $)$

\section{The experiments pouring PUR foam on inserts in mould}

For experiments pouring PUR foam to mould with inserts we use two approaches:

1. Using of PS inserts in mould

2. Using of faux wood or plywood

The main problem of using PS insert as insert in mould is in their chemical and physical instability. The main reason for next experiments was checking of reaction between PS (faux wood or plywood) machined insert and foam.

For experiments, we used next ways:

$>$ PS insert without separation

$>$ PS insert wax separation

$>$ PS insert paint foil $30 \mu \mathrm{m}$ separation

$>$ Wooden inserts wax separation

The results of experiments with $P S$

$>$ The results of PS insert without separation was destroying of PS insert by chemical reaction - there was a strong etching of the surface - unsatisfactory method

$>$ The results of PS insert with wax separation was partly destroying of PS insert by chemical reaction - there was a strong etching of the surface - unsatisfactory method

$>$ The results of PS insert with paint foil - this is satisfactory method (in terms of laboratory tests) - the results is demonstrated in Figure 4.

With regard to the shape of some of the shapes, this method of producing the mold would be difficult to apply to more shapes that are complex. The main reason would be to apply the foil so that it is straight and without folds. If a suitable way of separating the two materials is found, this method would be applicable in practice.

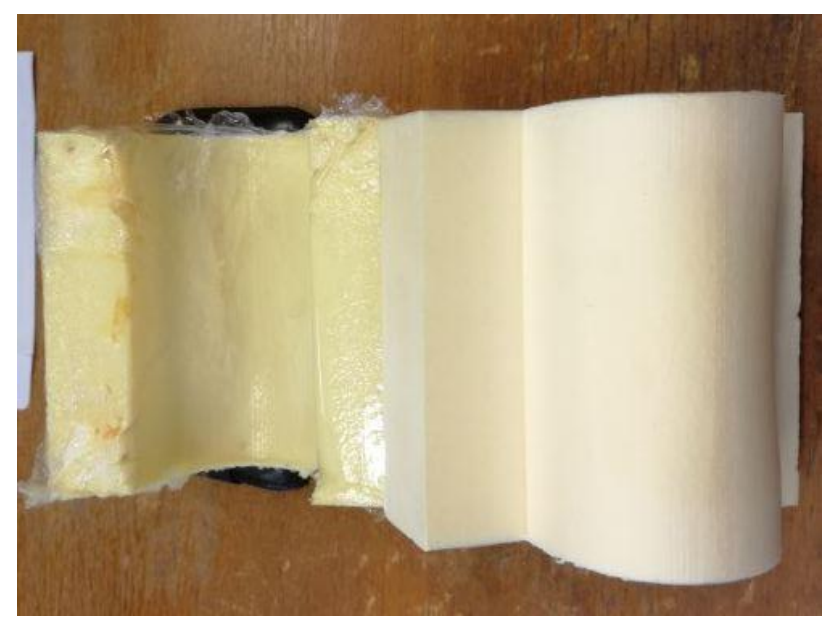

Fig. 4. Good results with using of PS insert and foil separation

For experiments with wooden inserts there was used separator wax (from previous research - using foil is complicated, mainly from reason achieving a good shape. This experiments is possible describe as the best - the surface of foam was very similar the surface of rolled glass (this is see on Fig. 5). 


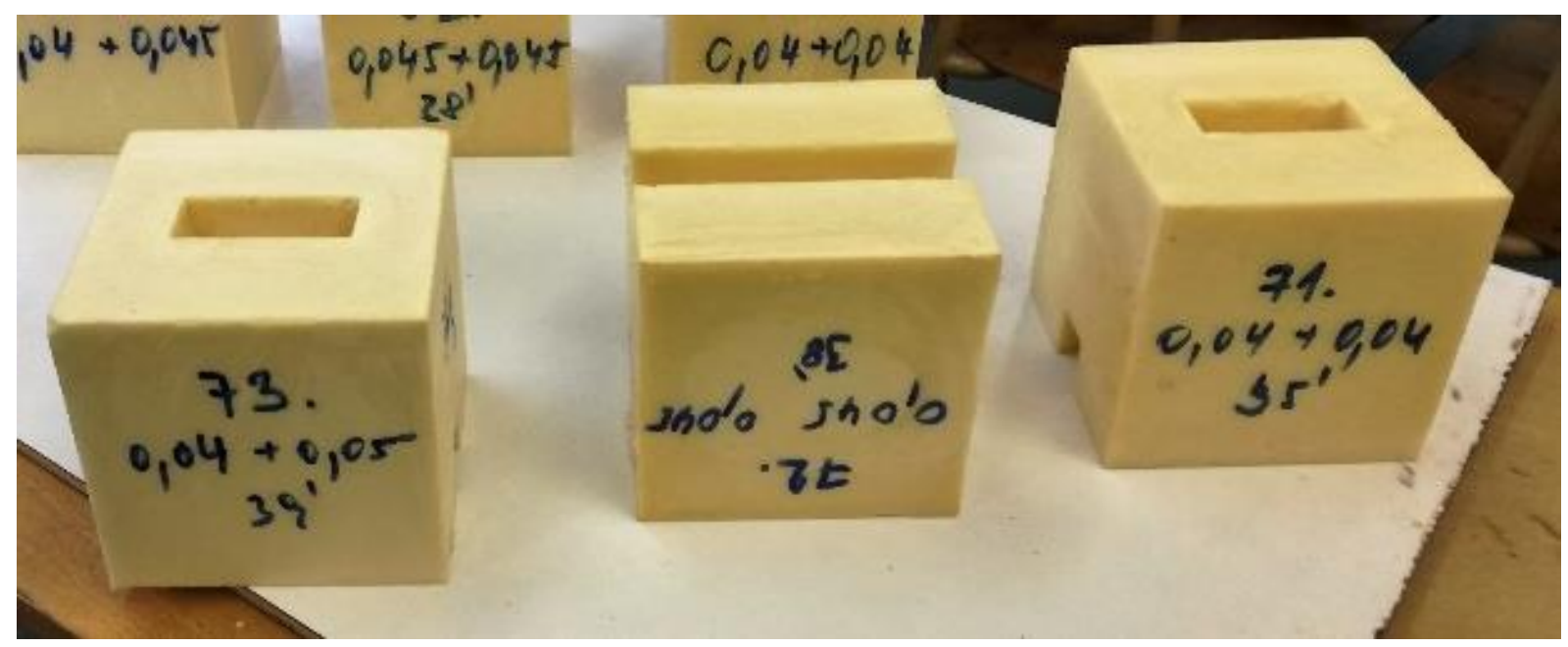

Fig. 5. Poured foam to shaped mould with wooden inserts - wax separation

Results from experiments with wooden inserts: From the point of view of copying the shape and the final smoothness of all the cavities and edges, it is clearly better for the PUR foam 2, where all the casting samples were compliant. The wrapping test further confirmed that the PUR1 and PUR2 materials are suitable for the construction of the inner parts of the prototype mold. The PUR2 material appears to be a better option before the mechanical resistance tests in prototype form.

\section{The experiments of machining and surface finishes after machining}

The machining tests of the proposed foam materials revealed a problem with the surface characteristics. The deficiency of foam polyurethanes after machining is the rough surface caused by internal pores. Extruded polystyrenes are not completely functional from the functional point of view as a molding material also. The surface is not very resistant to mechanical damage and the durability of the resulting product for reuse would be very low. That is why research has been looking for materials to suppress these shortcomings. Porosity will affect the surface appearance of the molded fitting and it is therefore necessary to ensure that the contact surfaces of the mold are as smooth as possible while maintaining accuracy.

Experimental methods for treating the machined surface of the cubes from the test materials include:

- Spray with colourless varnish mixed with talcum (type of kit) (see Fig. 6)

- Wax paint

- Use interchangeable paint

- Bodybuilder sealant

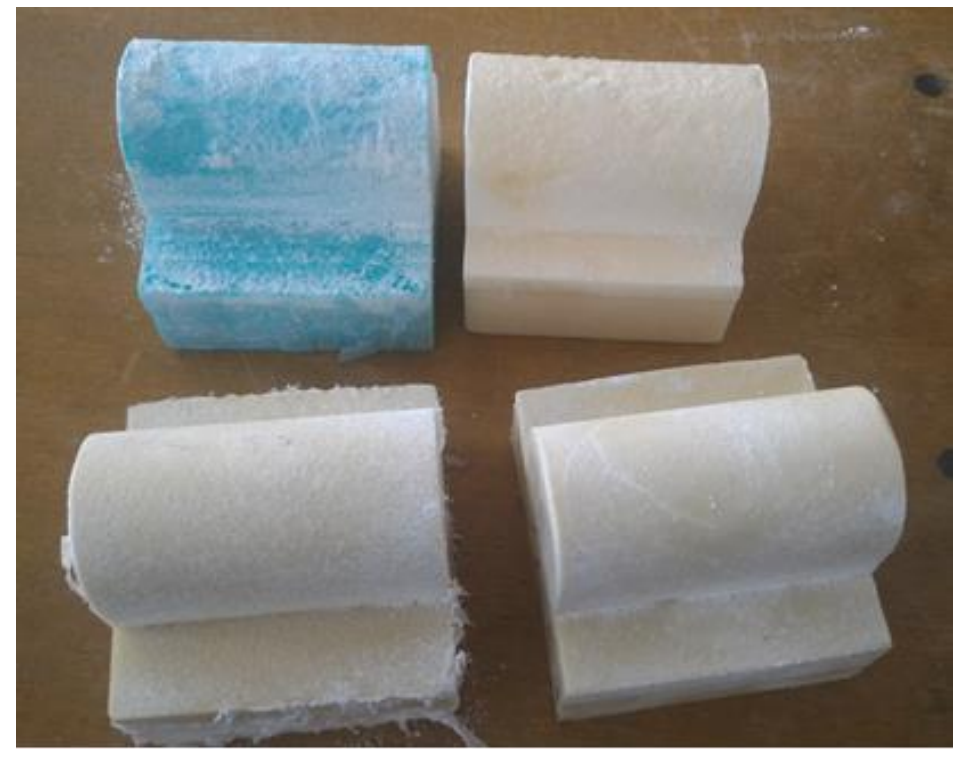

Fig. 6. Catching by talcum 
In spite of all the efforts, by any of the proposed methods in the first surface treatment tests the porosity was not solved. A mould shape change was proposed to test the behaviour of the foam when obstructing obstacles and the ability to fill the shape and achieve the accuracy and smoothness of the mold. The smoother surface of the cube was achieved more likely by precise casting than subsequent machining in combination with the casing. This knowledge is important for the further development of experiments as well as for prototype the mould conception. Due to the fact that the results of the surface treatment experiments were not positive, a foam pore shape analysis was carried out using methods of metallographic sample preparation and light microscopy. A sample of the cut is shown in Fig. 7.

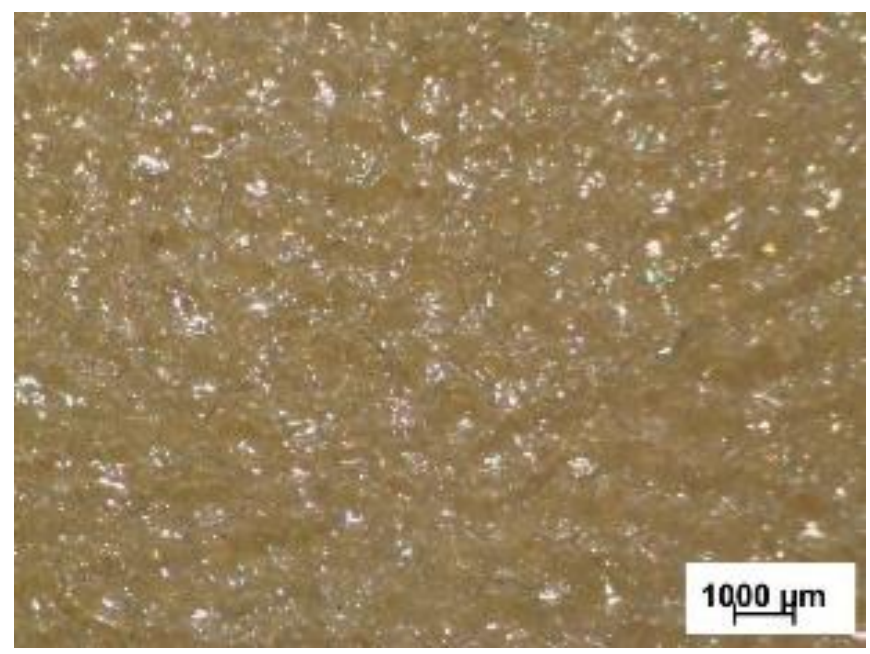

Fig. 7. Metallographic evaluation of foam PUR1 - 8x magnified

These cuts have explained why it is so complicated to catch - bubble shapes are regularly round and smooth. Therefore, despite the desire to use different types of cementing agents, the formation of completely continuous surfaces will not be achieved because the application of the surface treatment materials described above does not give rise to a sufficiently thick layer to fill the surface profile while ensuring sufficient smoothness and dimensional accuracy. Form precision and surface quality is a priority for the production of fittings in the required quality. Based on laboratory and semi-operative tests, we concluded that from aspect the ability to foam of moulds and surface quality to prove advantageous mixture PUR2 (Izopianol 50/48) - see Table 3.

\begin{tabular}{|l|c|c|}
\hline & PUR 1 & PUR 2 \\
\hline Surface quality & 3 & 4 \\
\hline Foaming of space & 3 & 3 \\
\hline Toughness & 4 & 2 \\
\hline Cost (small package) & $14000 \mathrm{Kč} / \mathrm{m}^{3}$ & $5400 \mathrm{~m}^{3}$ \\
\hline
\end{tabular}

Table 3. The evaluation of all laboratory and semi operational tests ( 1 - the worst, 5 - the best)

\section{Conclusion}

The advantage of the material was assessed both by technological and economic considerations. When comparing foam parameters, better results with PUR2 have been achieved, namely a better surface and a better foaming. The disadvantage of PUR2 is its lower stiffness, which is significantly lower compared to PUR1. For this reason, further experiments will be carried out in 2018, focusing on prototyping mold wear tests made from both materials, and examining the effect of the different stiffness of both materials. The PUR2 material is also significantly cheaper and would be less costly to use for mold manufacturing.

The best blend / volume parameters for casting into a 100x100x100 mm mold in terms of surface quality of the PUR 2 material are $0.045 \mathrm{dm}^{3}$ PUR A component and $0.045 \mathrm{dm}^{3}$ PUR component B.

Another conclusion of this experiment is the necessity of using the most rigid mold for casting boards due to the high pressures that the mixture produces when solidified. For this reason, other moulds will be made with a reinforced steel structure or the mold will be completely made of steel.

The cast plates produced a prototype form according to the material composition of the utility model. In 2018, material wear tests will be carried out on casting vibratory mixtures. Further, in 2018 tests of casting of PUR foam boards will be repeated in order to optimize the material composition of the prototype mold, the solidification process and minimize the change of the shape of the cast plates. 


\section{Acknowledgments}

This paper was created in cooperation with the company PD Refractories, Svitavy, and in the form of an economic contract under the project TRIO No. FV10057, „Development of the design and technology of mould production for refractory vibro-cast materials “.

\section{References}

[1.] Pivinskii, Yu.E., Nikitin, V.N., Khranovskaya, T.M. : Vibro-cast periclase refractories of a grainy structure and some of their properties, Refractories, ISSN: 00343102, DOI: 10.1007/BF01389513, Volume 27, Issue 7-8, July 1986, Pages 437-444

[2.] Shanmugasundaram, J., Annamalai, G., \& Venkateswarlu, B. (1988). Casting of concrete pipes by vibro-vacuum technique. Indian Concrete Journal, 62(7), 356-359. Retrieved from www.scopus.com

[3.] Richards, O., Rickard, I., Orr, J., \& Bisby, L. (2018). Response of concrete cast in permeable moulds to severe heating. Construction and Building Materials, 160, 526-538. doi:10.1016/j.conbuildmat.2017.11.097

[4.] Uotinen, L. K. T., Korpi, E., Hartikainen, A., Yorke, R., Antikainen, J., Johansson, F., \& Rinne, M. (2017). A method to downscale joint surface roughness and to create replica series using 3D printed molds. Paper presented at the 13th ISRM International Congress of Rock Mechanics, , 2017-January Retrieved from www.scopus.com

[5.] Formela, K., Hejna, A., Zedler, Ł., Przybysz, M., Ryl, J., Saeb, M. R., \& Piszczyk, Ł. (2017). Structural, thermal and physico-mechanical properties of polyurethane/brewers' spent grain composite foams modified with ground tire rubber. Industrial Crops and Products, 108, 844-852. doi:10.1016/j.indcrop.2017.07.047

[6.] Sherman, L. M. (2004). RIM/urethanes. Plastics Technology, 50(9), 84-85. Retrieved from www.scopus.com

[7.] GlassGlobal.com (https://www.glassglobal.com/consulting/reports/technology/ cited date 3.4.2018)

[8.] Sniezko, A., Papinski, J., \& Kaminski, R. (1987). Polyestrol for rigid polyurethane foams. [Purate T-230 poliestrol do sztywnych pianek poliuretanowych] Polimery/Polymers, 32(11-12), 459-463. Retrieved from www.scopus.com

[9.] França de Sá, S., Ferreira, J. L., Matos, A. S., Macedo, R., \& Ramos, A. M. (2016). A new insight into polyurethane foam deterioration - the use of raman microscopy for the evaluation of long-term storage conditions. Journal of Raman Spectroscopy, 47(12), 1494-1504. doi:10.1002/jrs.4984

[10.] Vojtko, I[mrich] \& Mikita, J[ozef]. Monitoring of Rheological Properties Of Polypropylene. Annals of DAAAM for 2011 \& Proceedings of the 22nd International DAAAM Symposium, Volume 22, No. 1, ISSN 1726-9679 ISBN 978-3-901509-83-4, Editor B. Katalinic, Published by DAAAM International, Vienna, Austria, EU, 2011 